\title{
An Analysis of the Current Situation of Single Window in International Trade in Mainland China
}

\author{
Chen Zhong, Chen Qinping \\ Research Center of Open Economics and Trade, \\ Fuzhou University of International Studies and Trade \\ Fuzhou, China, 350202
}

\begin{abstract}
Since the establishment of a single window of international trade, the study of single window has gradually become the hotspot of scientific research. This paper focuses on the study of many references, which are classified and sorted by the main contents of the previous academic journals and graduate thesis The paper presents the development trend and characteristics of the study on the single window of international trade in mainland China, and draws up its development trend and characteristics, and finds out the insufficiency of the study of single window and puts forward the new idea and new orientation of single window research.
\end{abstract}

Keywords—mainland China; single window; research; period

\section{INTRODUCTION}

Along with the reinforcement of reform and opening-up policy as well as the promotion of trade facilitation in the country, the single window system platform of international trade has been constantly promoted from the government to the people, and the diversified value expression brought thereby has been recognized by people. Currently, the single window of international trade has become the hotspot and key point for the academic research of foreign trade, and we also need to timely summarize and understand the current status about the domestic single window in the recent years, so as to define the research direction of single window in the future.

\section{THE BASIC CONCEPT OF SINGLE WINDOW AS WELL AS THE RESEARCH OBJECT AND OBJECTIVE OF THE PAPER}

\section{A. The basic concept of single window}

As per the definition given in UN/CEFACT Proposal No. 33 , single window "refers to a single entrance that can permit the various participators in the trade and transportation to submit standard information and documents, and meet the requirements of management institution related to private import, export and re-export". In short, it is a one-stop service window that can complete the various complicated procedures of international trade (handling the information and receipts involved thereby) [1]. Along with the development of contemporary internet information technology, single window can present characteristics of networked systematic platform, and diversified mode of operation (which can be operated through computer, cell phone, and other intelligent equipment).

\section{B. The research object and objective}

The author takes the period from January, 2012 to May, 2017 as the research period (hereinafter referred to as the period), and the academic journals about single window as well as the doctoral papers and master papers as the research object, aiming to understand the progress about the research of single window among the academic papers published in mainland China over above four years, and meanwhile, conduct characteristics summary and analysis, and then put forward the suggestions for the research of single window in the future.

\section{MAIN CONTENTS ABOUT THE RESEARCH OF SINGLE WINDOW AT HOME}

Currently, the contents of the research about the single window of international trade involve: the research about the construction and implementation scheme of single window, of which it includes the research about construction technology, the research about organization management, and the comprehensive research about construction technology and organization management; the research about the economic benefit of single window, of which it includes the income and cost analysis of single window; the basic theoretical research about single window; the research about the experience of single window; the research about the influence of single window; the research about the application of single window and other six aspects [2].

\section{A. The construction and implementation scheme of single window}

The construction and implementation of single window are the key focus fields for most domestic scholars. For instance, Gao Shuang (2014) respectively analyzed the division of labor for various characters in the construction framework system of single window, the classification and selection of operation mode, the support factors and other aspects as per the construction experience of overseas single window, put forward the suggestions about reinforcing the top design for the construction of single window at home, perfecting the legal environment, unifying the trade data standard and implementation [3]. 


\section{B. Economic benefits of single window}

The economic benefits of single window can be reflected in the relation between input and output, and in light of the input cost, the construction cost of single window is relatively high, but few domestic scholars are involved, and this may be related to the failure for most university scholars in directly participating in the construction; besides, the specific construction is mostly executed by the government department, and the relevant finances are not fully opened, either.

However, with respect to the generation, for the promotion of time efficiency and the increase of service object, etc., the domestic scholars have conducted the collection and sorting of big data, for instance, Chen Lilin (2016) applied the big data analysis in the Discussion about the Promotion Role of Fujian Electronic Port in Foreign Economy, and then adopted the quantitative mode, to express that, since the public platform of Fujian Provincial electronic port was operated, it had directly served more than 4,400 enterprises, indirectly served above 30,000 foreign trade enterprises, and above 35,000 daily document handling quantity. The customs inspection time was shorted to 5-10min from 4 hours before. The entry and exit time of ships was shorted to 2.5 hours from 36 hours before. As per the data provided by UN/CEFACT, the international trade convenience measures can annually save USD 1 trillion for the world trade [4].

\section{Basic theory of single window}

In the construction process of single window, introduce the relevant principles to optimize the single window, and exert the theoretical value, for instance, in the paper about building the principle and methods of single window for trade as well as the analysis of core contents, Hu Hanjing, Zhang Mengfen, and Yang Qinghai (2017) respectively set out the target principle, the principle of applicability, the principle of consistency, the operable principle, the extension principle, and the regulatory principle for building the single window of trade, and meanwhile, put forward the proposal for using ISO 9000 management methods based on modern science management to build the single window of trade. To build the single window of trade, three big core issues must be solved, including the feasibility research, the simplification and standardization of trade data, and the legal management of single window [5].

\section{Experience of single window}

Along with the construction and promotion of single window as well as the successive summarization about the construction experience of single window at overseas countries and various places nationwide, references can be provided for the development of single window in the future.

Li Mengjia narrated in the Master's Graduation Paper-the International Experience Reference and Route Selection for the Development of Single Window in Our Country considering the development of single window in various main countries, and put forward that the automatic data handling system can be adopted for constructing the single window in China, but the key is to form true public platform through the integration of virtual institution, and form true public platform, so as to coordinate the interests of various departments. Besides, in the development of single window, it is also applicable to firstly build the local single window in economic developed areas (Yangtze River Delta, and Pearl River Delta), and then take Chinese electronic port as the basic platform, and the development of local single window as the experience, to unify the single window platform of country version. After that, it is also applicable to dock with the single widow of European Unison and ASEAN in the future through the standard and international development of data [6].

In Deeply Promoting the Construction of "the Single Window" of International Trade in Shanghai, Ma Haiqian, and Zhu Chunlin (2012) pointedly summarized problems, described the reasons, put forward the necessity to optimize the single window functional plate, and build perfect operation and maintenance mechanism considering the current status about the construction of single window in Shanghai, and then build "mixed system type" (the basic function is handled by the direct platform of customs and commodity inspection, and the rest functions will be transmitted to other institutions for treatment) single window considering the diversity of management department) single window [7].

\section{E. Influence of single window}

The comprehensively analysis on the influence generated by single window has become the main field for the quantitative research of single window abroad, and the influence of foreign investment quantity in our country can be analyzed through the influence of single window development on the quantity and variety of export commodities. However, the development for the research about the influence of single window at home is equivalent to one new thought.

In the doctoral paper, Wang Wei (2016) conducted empirical research about the export trade competitiveness of single window in China, and concluded series of influences brought by trade convenience represented by single window: (1) Generating the structure optimization of Chinese export goods, and the diversification for the countries and regions involved in the export trade. (2) Decreasing the economic cost and time cost of enterprises, and converting them into price advantages; increasing the opportunity for transnational corporations to enter into the market of our country; promoting technical progress, and finally promoting export competitiveness [8].

\section{F. Application of single window}

For the application of single window in specific fields, and then the reflection of practical value for single window, and the true reflection of research significance for single window, some scholars are now constantly reinforcing the in-depth degree for the application of single window.

Guo Jianfang (2017) specifically elaborated the convenient effect exerted by single window in the cross-border e-business of Zhejiang. Zhang Mingzhou (2014) conducted the application research about the standard promotion of international trade voucher, and then analyzed the understanding of foreign trade enterprises and students studying foreign trade in higher vocational colleges through questionnaires. He put forward the request to set up national standard for foreign trade voucher, and unify the standard and promote such standard; meanwhile, 
he also suggested the reinforcement of the understanding of students majoring in the international trade of universities for single window [9].

In the Discussion about the Port Department Cooperation and the Construction of Simplified Customs, Guo Yongquan (2016) put forward that it was applicable to adopt the opinions of game theory, and then link up and unify the customs, the inspection and quarantine in the two business nodes of declaration and release, the possession and port as well as other regional nodes, of which single window is an important platform, so it is requested to promote the exchange of its standard information [10].

It shall be pointed out that, although the contents about the research of single window at home can be divided into six aspects, scholars don't mostly conduct single and separate research in the research process; on the contrary, there is certain emphasis.

\section{MAIN CHARACTERISTICS ABOUT THE RESEARCH OF SINGLE WINDOW AT HOME AS WELL AS THE EXISTING PROBLEMS}

As per the research about the relevant academic papers during the current period, the author has found that the domestic research for the single window of international trade has three big characteristics. The first one is to refer to the scientific achievements of overseas advanced experience in single window, and then constantly make refinement and diversification.

The construction of single window for a part of overseas countries and regions is started very early, with good actual operation effect, and it has always been the object for the comparative study of domestic scholars.

Liu Enzhuan and Wang Wei (2014) reviewed the development history about the single window of international trade in Singapore, pointedly introduced the approach adopted by Singapore through utilizing the local enterprises to accelerate the integration of comprehensive platform for single window, and meanwhile, conduct the customs clearance data sharing with some overseas countries, so as to promote its clearance efficiency. For the construction of the single window of international trade in China, it is applicable to refer to its absorbed enterprises, to participate in the construction of single window, but it is requested to combine the foundation of former foreign trade port in China, and increase the guidance of government public platform, so as to coordinate the interests of various government departments participating in the single window, and then form the resultant force of management [11].

Yin Fei, and Feng Yun (2015) studied the system experience about the single window of international trade in Singapore, and then form mechanism through the horizontal comparison of single window in America, Sweden, Netherlands and other countries, and expressed affirmation on the success for applying the government and social capital cooperation (PPP) mode in Singapore, put forward referential PPP mode, and meanwhile, progressively promoted the development of the single window of foreign trade under the lead of unified management department specially set for single window [12].

Gong Jiaqi, Li Mingyao and Wang Ming (2015) et al. comprehensively introduced the general development situation about the single window of America, combined the development conditions about single window in China, and put forward suggestions, such as reinforcing the industrial liaison, promoting the liaison between China Customs and various other organizations considering the single window, reinforcing the publicity to obtain the recognition and support of the entire society, perfecting laws and regulations as well as matched technologies, fund support and other suggestions [13].

Liang Danhong (2015) summarized the historical experience for implementing ACE/ITDS technologies in the construction of single window for America, and put forward that China could refer to the American experience from three aspects, including establishing the management mechanism with clear objective, implementing "de-departmentalization" data management, and innovating the application of single window platform [14].

Wang Wei (2017) reviewed the construction progress about the single window of trade in Korea, and meanwhile, analyzed that the service provided thereby involved several subsystems, such as the trade portal website, the network customs clearance support system, logistics service network, etc., and meanwhile, conducted simple qualitative and quantitative descriptions about the efficiency. Wang Wei held that the publicity force of Korean government was big, and beneficial to the progress and promotion of single window, but as for the development of single window at home, it was applicable to refer to the optimization of legal environment for single window, pay equal attention to the rights and obligations of the leading institution and coordinated institution, define their posts, and meanwhile, conduct perfect legal guarantee for the information coordination and data sharing in the single window. Besides, it was also suggested that international standard should be adopted in the acquisition, definition and handling of information, when building single window [15].

Secondly, the research shall be combined with the new hotspots of foreign trade in China, and the scholars start to put forward suggestions for the function of free trade zone, crossborder e-business and other new policies and new things in single window or the considerable reform of single window for new hotspots, etc.

In the Analysis on the Trade Convenience Measures Comparison and Innovative Development for the Free Trade Zone of Our Country, Gao Yunsheng (2017) mentioned the practice of single window in the free trade zone, and suggested that Shanghai, Zhejiang, Suzhou, Anhui and Yangtze River Delta region should jointly build single window, and then accelerate the promotion of unified information platform, and realize cross-department data exchange and sharing between the government and enterprises, and then realize "customs clearance in various places, just like they are one customs" in the free trade zone. In the Cross-border E-business Development Evaluation Index Research Based on AHPTaking Zhejiang Province as an Example, Guo Jianfang pointed out that, the development of cross-border e-business 
was directly related to the convenience of single window, the convenience of customs clearance and inspection, the convenience of electronic tax refunding and other indexes [16].

In the Innovative Mechanism Research of Customs Management Mode in the Free Trade Zone, Jin Bicheng, Yang Yicheng and Fang Lei (2015) found out the following problems after investigating the user information: (1) there are too many platforms in each department, and the system has incompatible phenomenon, which has resulted the users in repeatedly submitting information, and generating too many submitted documents, and then restricted the platform efficiency; (2) due to the incomplete of new system, abnormal cargo handling will be incurred; (3) the investigation has showed that the voucher circulation time in each customs department is long, the service awareness is not put in place, the departments don't want to adjust the management region, and the right reform still needs to be further reinforced [17].

Thirdly, the research has started to pay attention to the handling of specific effect.

For instance, how to perfect the data structure to be collected considering the data source of single window; in the Research about the Establishment and Application of Single Window Data Element Set for International Trade, Liang Danhong (2014) suggested that single window needed to set perfect data structure, including the data element quantity, the data element name, the data element description, representation notation, data field, transportation mode, process, using type, the legal permit of data collection and consulting, the source of authorization, the expiration date of authorization, the data source, and trade source, and through the data analysis of these data, redundancy can be reduced, and then finally be coordinated into standard data element [18].

During the period of studying the scientific research paper, the author has found out the main problems existed in the current research of single window at home:

\section{A. The group of research scholars is lack in the joint research of cross-system}

Through randomly selecting 100 journal articles of the research scholars about the research of single window, from the perspective of scientific research author (the first author), as shown in the following figure, it can be found that, scholars studying the single window of international trade are personnel from government institutions (occupying 10\%, and mostly, they are customs, provincial and municipal development and reform commission, including the public institution affiliated to institutions), scholars in universities (occupying 89\%) and also working personnel from companies and enterprises (occupying $1 \%$ ), and the authors of papers are mostly from the same unit, or the same system unit. Few paper scholars involve crosssystem joint research.

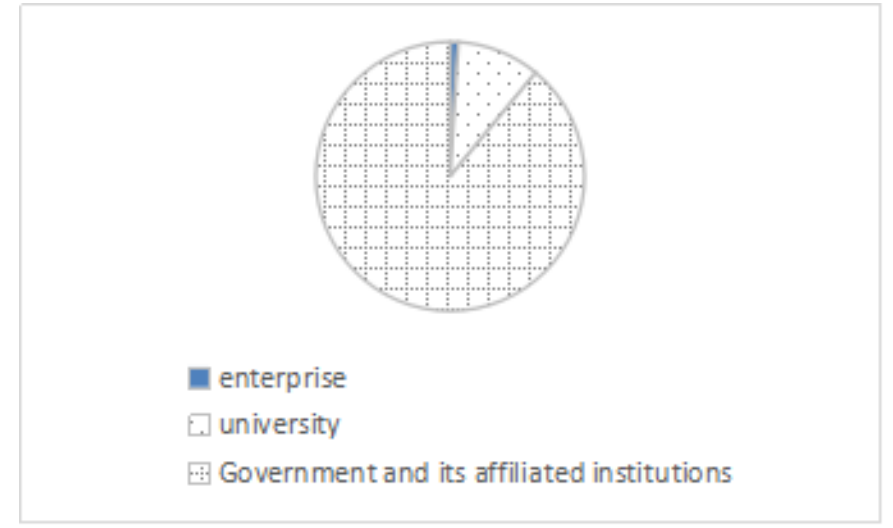

Fig. 1. Conditions about the Units of Authors Publishing the Journal Article

\section{B. There are few researches involving specific in-depth issues}

The general direction of research is still focused on referring to the overseas experience, and there are few published papers studying the standard operation of specific data, how to coordinate the interests of all departments in single window and the solutions for solving the existing problems in the practice of single window in various provinces and cities, and these can be some key points and difficult points for us to study in the future.

\section{The support in studying the relevant models in the research process}

Most researches are kept at the layer of subjective policy discussion, mechanism discussion, or the comparison of Chinese and foreign single window, so when being compared with the western in-depth reference mode for the empirical analysis of single window [19], the theoretical foundation is relatively weak.

\section{SUGGESTIONS RELATED TO THE FUTURE RESEARCH OF SINGLE WINDOW AT HOME}

In light of the existing problems in the research of single window, and the current development of single window at home, the author suggests that the following contents can be considered when studying the single window:

(1)The government agencies of the state jointly cooperate with the specific department and scientific research universities to conduct specific investigation and joint research considering the single window management right distribution, and the interest coordination, and then lower the management cost in the practice of single window, improve the management efficiency, set such major scientific research topics, and provide strategies or legal guidance for the reform of government mechanism in the future.

(2)In the research about the standard handling of data and the feedback problems used in the single window of provincial and municipal local enterprises, emphasize on the participation of enterprises, including the enterprises and $R \& D$ development applying single window, and all of them can participate in the scientific research topic research in universities, so as to 
promote the guarantee function of research for the solutions of specific problems.

(3)Currently, the country is now practicing the promotion of standard version of single window, and as the institutions, universities and relevant enterprises of main provinces and regions that will participate in the practice, they should especially take active actions, summarize the problems and disadvantages exposed in the linkage between the national standard version of single window and the provincial single window, and provide actual methods for the national standard version of single window.

\section{CONCLUSION}

For the research about the single window of international trade in China, the currently main research contents involve 6 aspects: the research about the construction and implementation scheme of single window; the research about the economic benefits of single window; the basic theoretical research of single window; the research about the experience of single window; the research about the influence of single window; the research about the application of single window, and most researchers are conducting cross-aspect research. The characteristics for the research of single window include: 1 . during the research, refer to the research achievements for the advanced experience of overseas single window, constantly make refinement and diversification; 2. combine the research with the new hotspots of current Chinese foreign trade; 3. start to pay attention to the handling of specific effectiveness in the research. In the research of single window, there are still several problems as follows: 1. the group of research scholars is lack of cross-system joint research; 2 . the research involves few in-depth issues. Thus, the author holds that, for the future research, the national government institutions can jointly cooperate with the specific department and the scientific research universities to specifically investigate and jointly study the single window management right distribution, and profit coordination; in the research about the feedback issues of standard data handling, provincial and local enterprises in the use of single window, and emphasize on the participation of enterprises; regard the promotion practice of currently promoted standard version of single window as the key point of the research.

The construction of the single window of international trade is a long-term and dynamic system work, and also the important work related to the long-term development of international trade in our country; it is believed that, with the participation of multi-dimensional scientific research practice, a strong resultant force can be provided for the successful implementation of such work.

\section{REFERENCES}

[1] UN/CEFACT Recommendation No. 33"Establishing a Single window".

[2] Wang Wei, and Liu Enzhuan. Research Review and Expectation about the Single Window of International Trade [J]. Prices Monthly, 2017 (01):72-76.

[3] Gao Shuang. Research about the Construction Mechanism and Implementation Countermeasures for the Single Window of International Trade [J]. Productivity Research. 2014(14): 74-77, 136.

[4] Chen Lilin. Discussion about the Promotion Role of Fujian Electronic Port in Foreign Economy [J]. Straits Science 2016(07): 85-87.

[5] Hu Hanjing, Zhang Yinfen, and Yang Qinghai. The Principles and Methods for Establishing the Single Window of Trade and the Analysis of Core Contents [J]. China Standardization 2017(05): 33-36.

[6] Li Mengjia. The International Experience Reference and Route Selection of Single Window in Our Country [D]. Tianjin: Tianjin University of Finance and Economics. 2015 (07)

[7] Ma Haiqian, and Zhu Chunlin. Deeply Promoting the Construction of "the Single Window" of International Trade in Shanghai [J]. Scientific Development. 2016(05):48-53.

[8] Wang Wei. Research about the Influence of the Single Window of Trade on the Export Competitiveness of China [D]. Tianjing University of Finance and Economics: 2016(05)

[9] Guo Jianfang. Research about the Cross-border E-business Development Factors of Zhejiang [J]. Computer Knowledge and Technology. 2016(12): 289-290.

[10] Guo Yongquan. Discussion about the Port Department Cooperation and the Construction of Simplified Customs [J]. China Opening Journal. 2016(03): 70-74.

[11] Liu Enzhuan, and Wang Wei. Brief Analysis on the Enlightment of Single Window Construction of Singapore for the Construction of Our Country [J]. Science and Technology Management Research. 2014(24): 195-198.

[12] Yin Fei, and Feng Yun. Singapore International Trade "Single Window" System Experience and Enlightment [J]. China Economic \& Trade Herald. 2015(18): 27-29.

[13] Gong Jiaqi, Li Mingyao, Wang Ming, el. Brief Analysis on the Enlightment of American Single Window Construction for Our Country [J]. Abstract Version: Economic Management. 2015(2): 252, 257.

[14] Liang Danhong. The Implementation and Enlightenment of American Single Window ACE/ITDS [J]. Customs and Trade Research. 2016(05): 1-17.

[15] Wang Wei. The Construction and Enlightenment of Single Window for Korean International Trade [J]. Contemporary Economics. 2017(05): 106-109.

[16] Gao Yunsheng. The Analysis on the Trade Convenience Measures Comparison and Innovative Development for the Free Trade Zone of Our Country for the Free Trade Zone of Our Country [J]. Journal of Hunan Administration College, 2017(1): 39-44.

[17] Jin Bicheng, Yang Yicheng, and Fang Lei. The Innovative Mechanism Research of Customs Management Mode in the Free Trade Zone [J]. Jiangsu Commercial Forum, 2015 (8): 125-126.

[18] Liang Danhong. Research about the Establishment and Application of Single Window Data Element Set for International Trade [J]. Customs and Trade Research 2014(06): 1-9.

[19] Katerina Tosevska-Trpcevska.Effects of the Implementation of Single Window and Simplified Customs Procedures in the Republics of Macedonia [J]. World Customs Journal, 2014(08): 52-54. 